Supporting Information

\title{
Highly Strong and Solvent-Resistant Cellulose Nanocrystal Photonic Films for Optical Coatings
}

Fusheng Zhang, ${ }^{\dagger,}$ Wenna Ge ${ }^{\S}$ Cunli Wang, ${ }^{\dagger}$ Xintong Zheng, ${ }^{\dagger}$ Dongdong Wang, ${ }^{\dagger}$

Xiancheng, Zhang, ${ }^{\dagger}$ Xue Wang, ${ }^{\dagger}$ Xingya Xue ${ }^{\dagger, \ddagger}$ and Guangyan Qing $*, \uparrow,+, \|$

${ }^{\dagger}$ CAS Key Laboratory of Separation Science for Analytical Chemistry, Dalian Institute of Chemical Physics, Chinese Academy of Sciences, Dalian 116023, P. R. China

Wniversity of Chinese Academy of Sciences, Beijing 100049, P. R. China

${ }^{\S}$ School of Mechanical Engineering, Dalian University of Technology, Dalian 116024, P. R. China "Key Laboratory of Advanced Energy Materials Chemistry (Ministry of Education), College of Chemistry, Nankai University, Tianjin 300071, P. R. China

Email: qinggy@ dicp.ac.cn 


\section{Supporting figures}

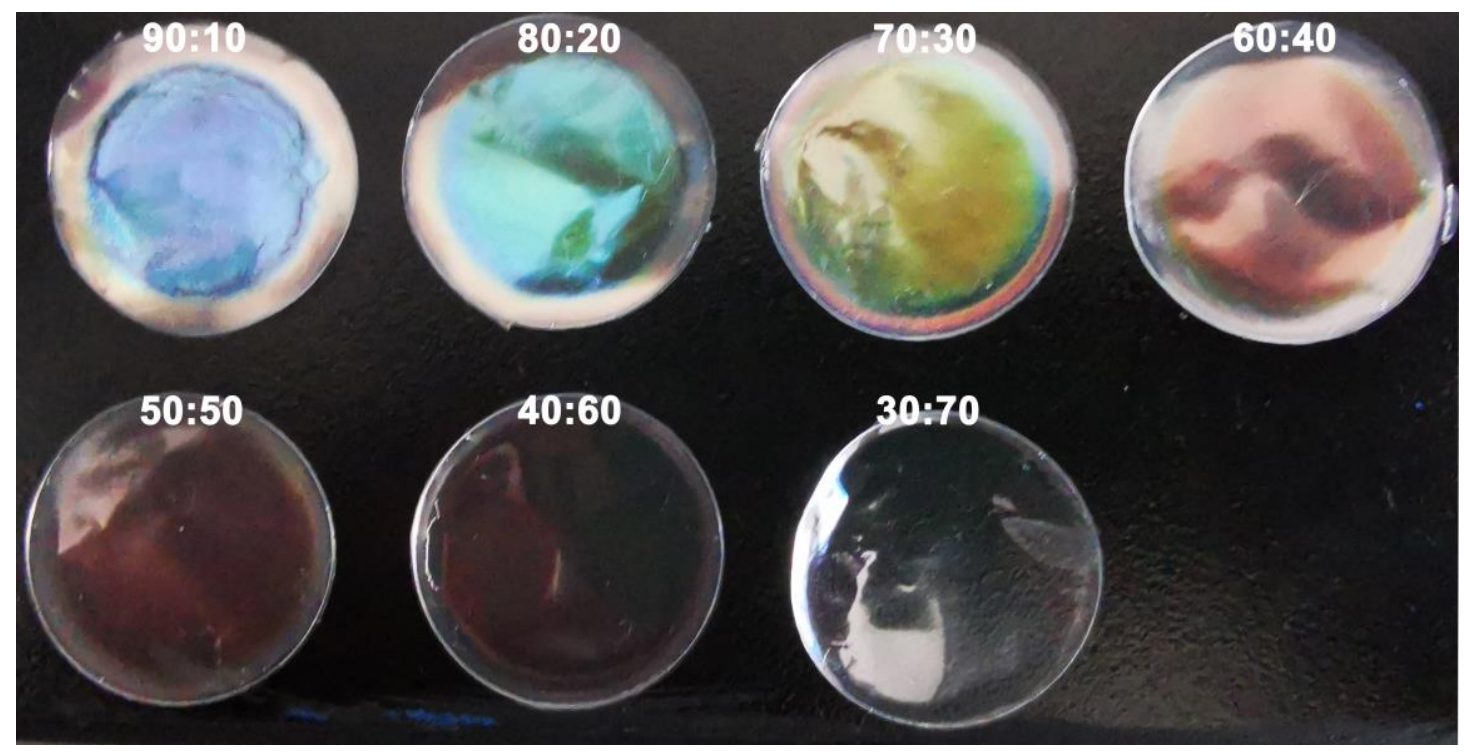

Figure S1. Photographs of CNC/PVA composite films with different ratios (diameter: $25 \mathrm{~mm})$. 

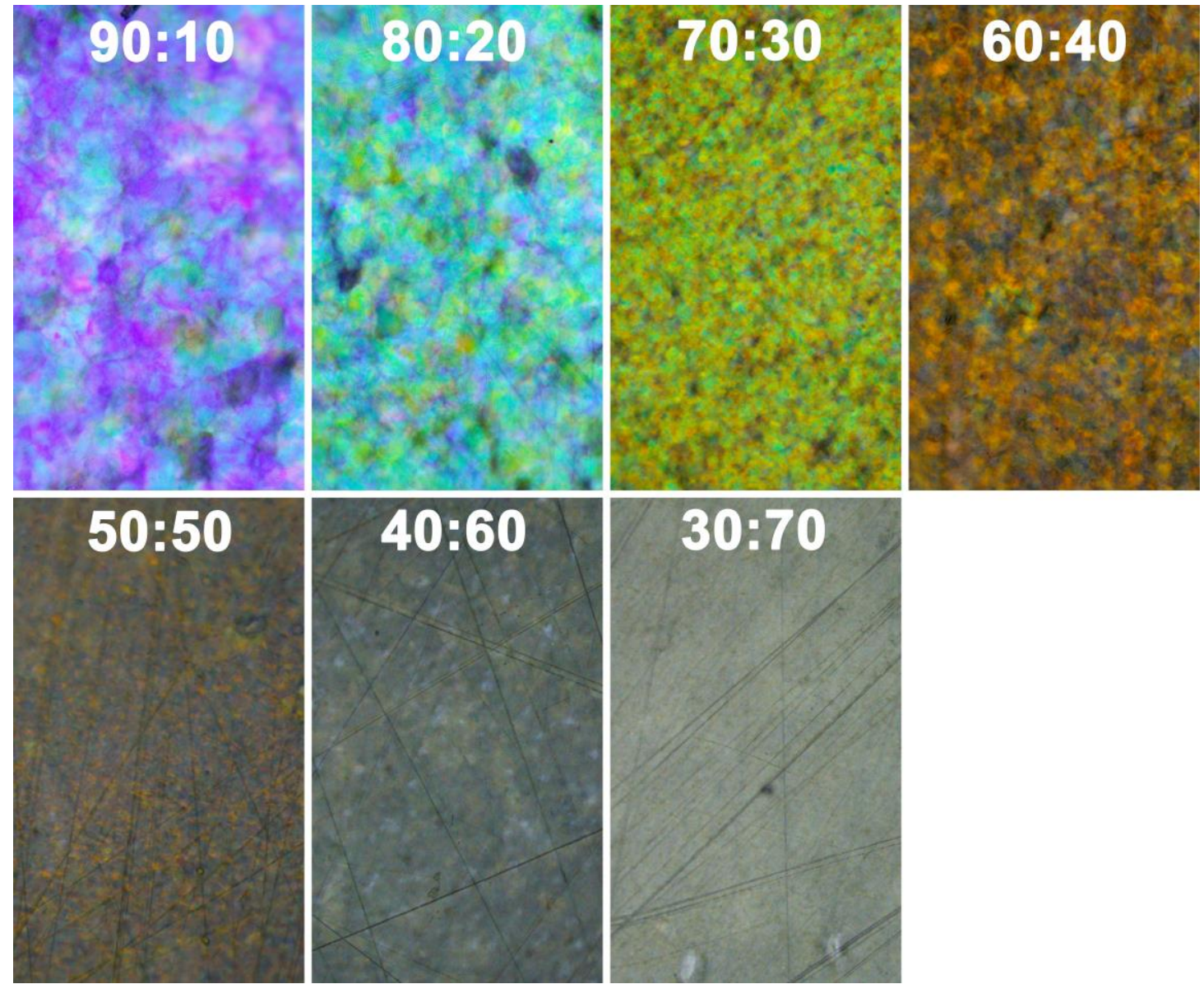

Figure S2. POM images of prepared CNC/PVA composite films. 


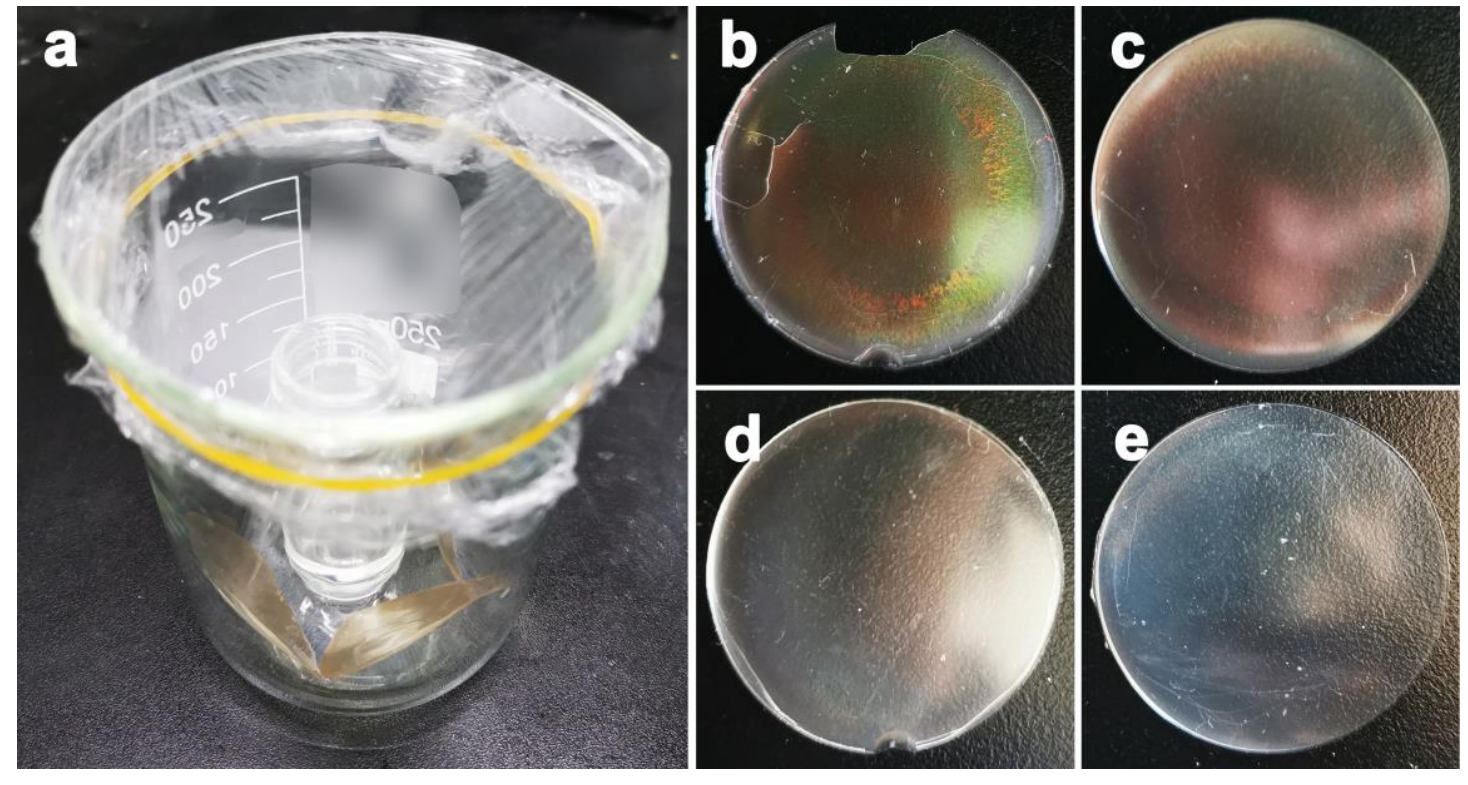

Figure S3. Process of glutaraldehyde (GA) cross-linked CNC/PVA film with $\mathrm{HCl}$ vapor (a). Photographs of different ratios of GA-cross-linked CNC/PVA film from 0.5 (b), 1.0 (c), 1.5 (d), to $2.0 \mathrm{wt} \%$ (e). 


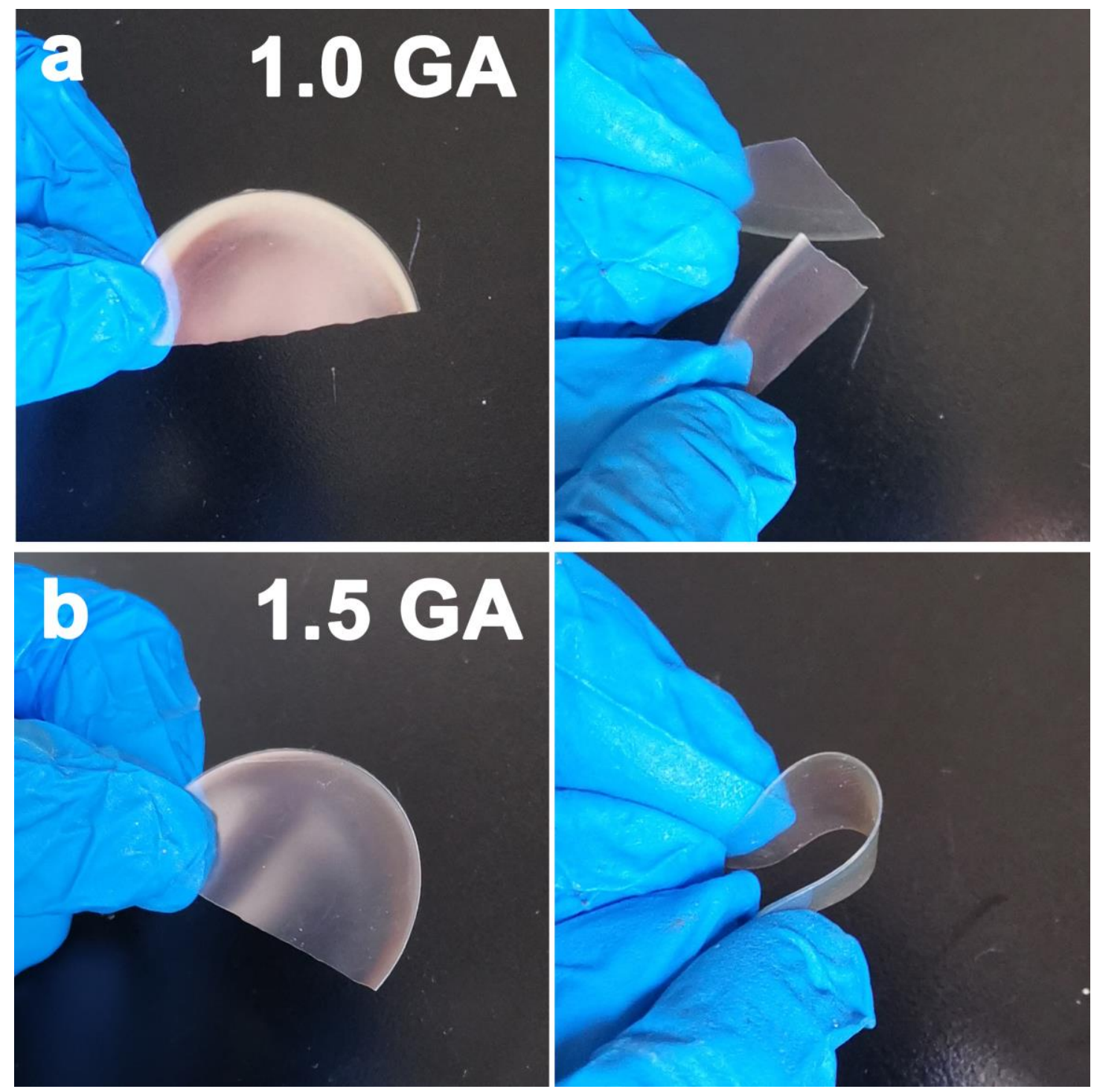

Figure S4. Photographs of GA-cross-linked CNC/PVA film before (left) and after (right) bending. (a) CNC/PVA-1.0 wt \% GA and (b) CNC/PVA-1.5 wt \% GA. 


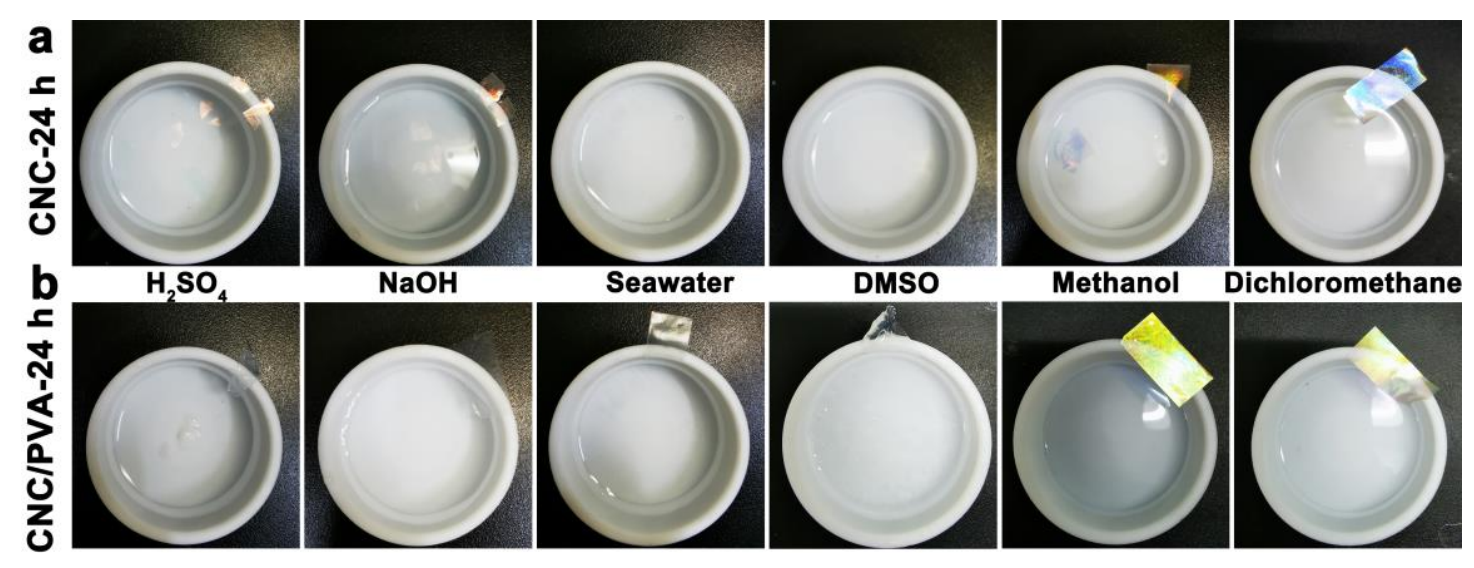

Figure S5. Photographs of CNC and CNC/PVA-70:30 films after being immersed in various solvents for $24 \mathrm{~h}$. 


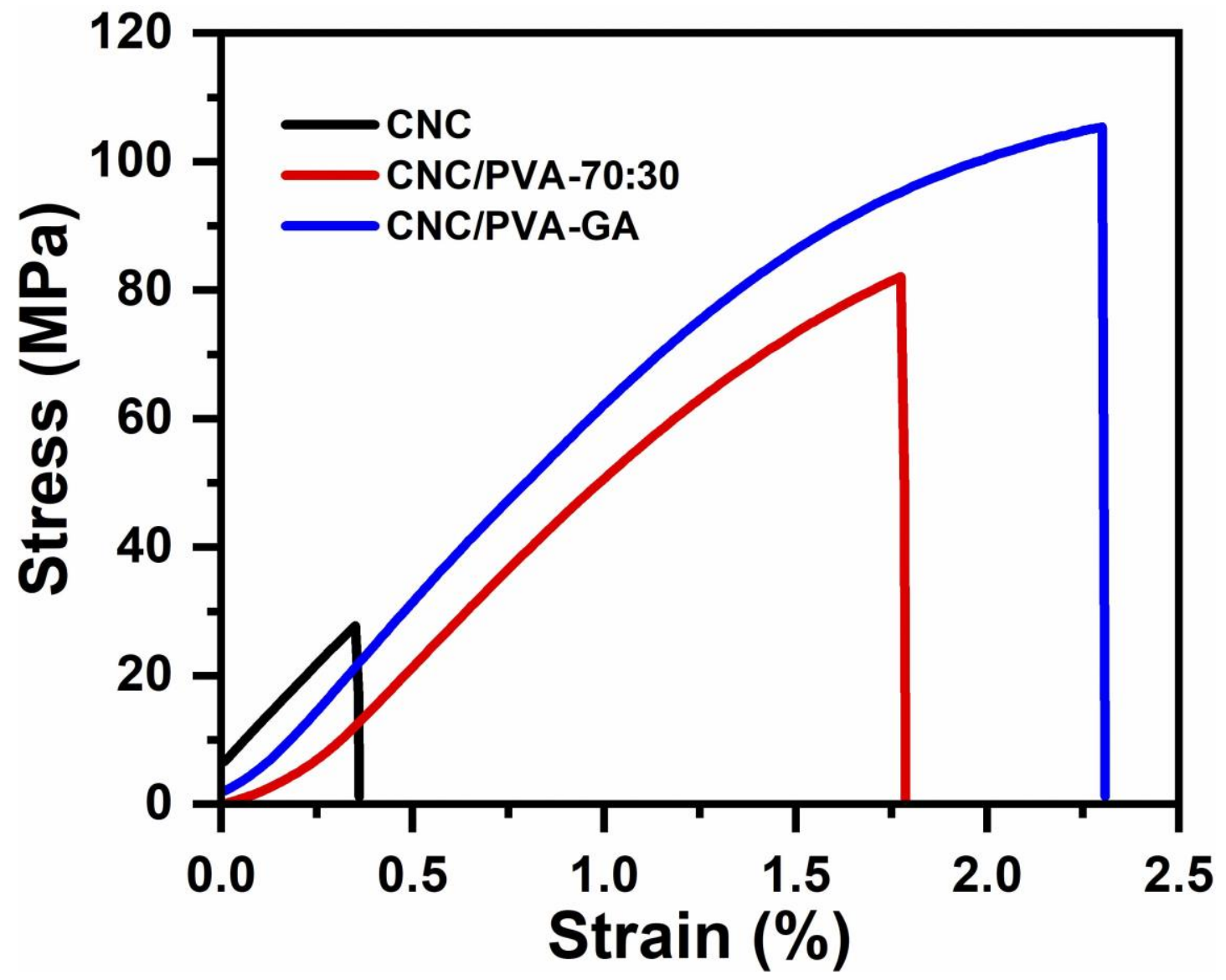

Figure S6. Stress-strain curves of pure CNC, CNC/PVA-70:30, and CNC/PVA-GA films after stabilizing at the RH of $80 \%$ for 2 days. 


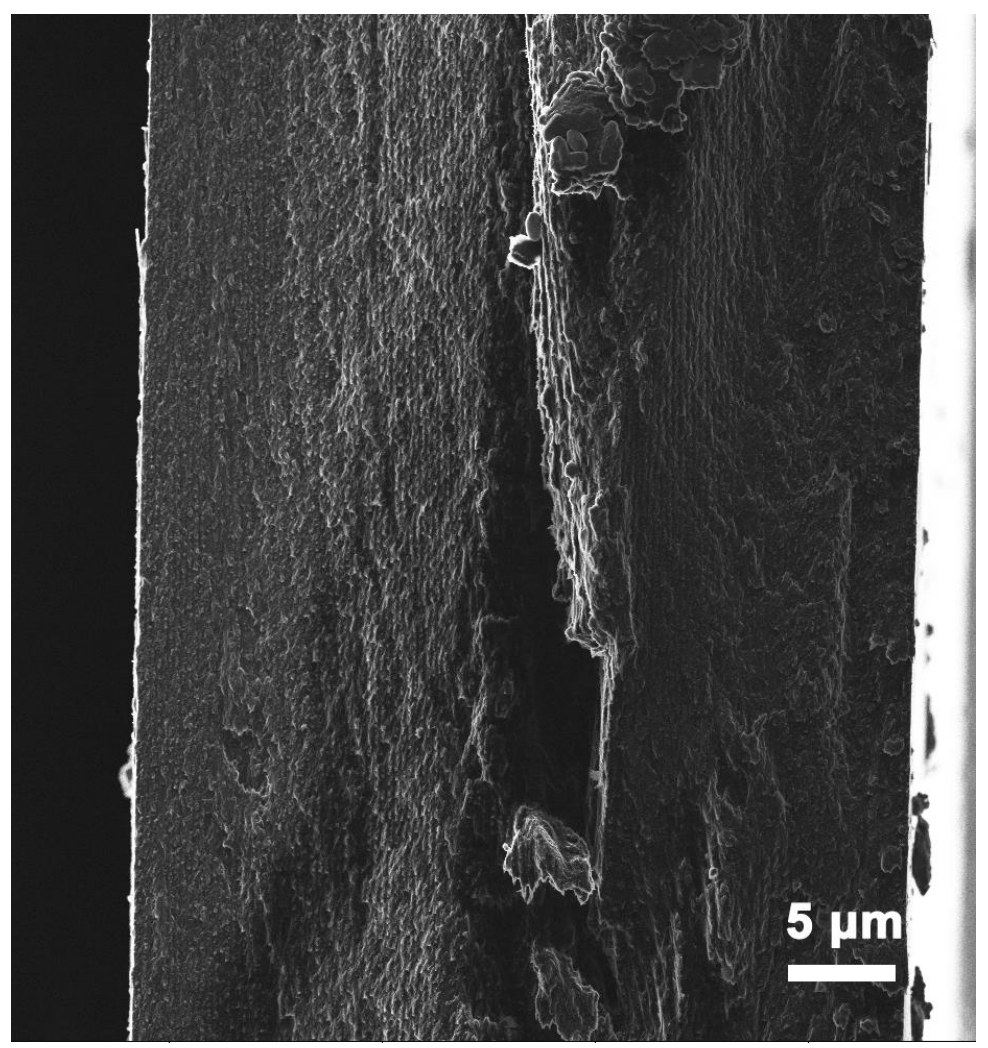

Figure S7. SEM micrograph of the cross-section of CNC/PVA-GA film. 


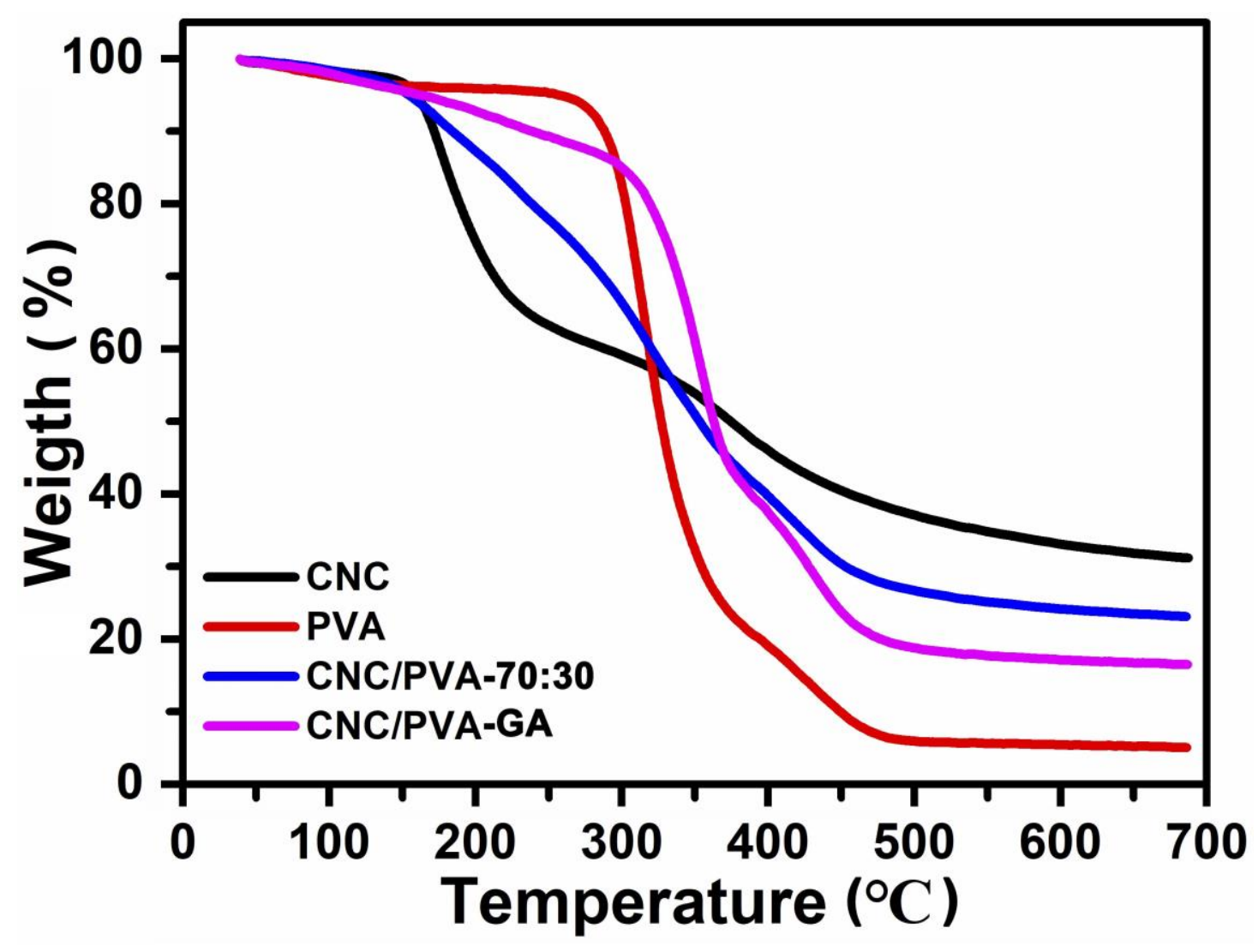

Figure S8. Thermogravimetric analysis curves of CNC, PVA, CNC/PVA-70:30, and CNC/PVA-GA films. 


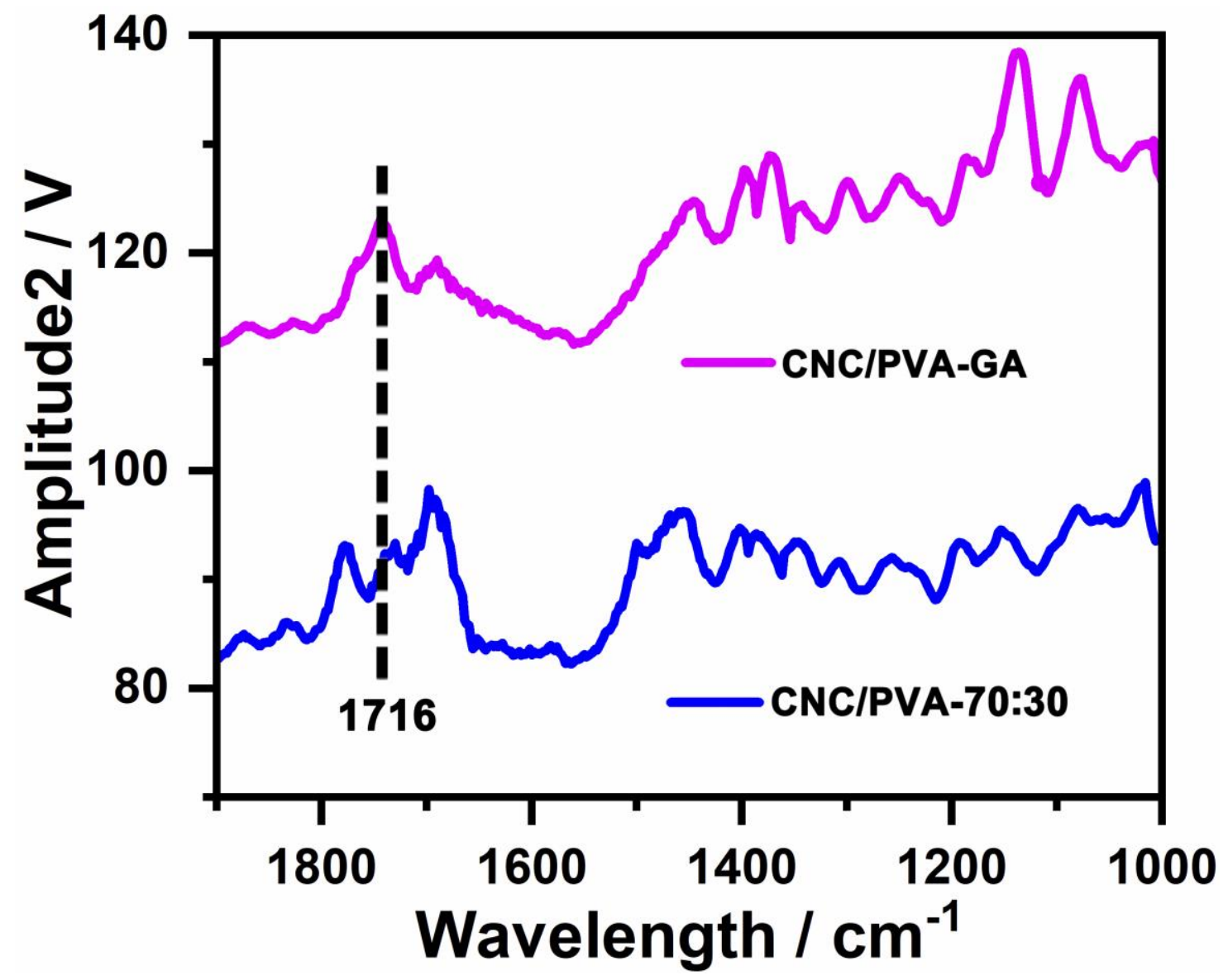

Figure S9. AFM-IR spectra were recorded for CNC/PVA-70:30 and CNC/PVA-GA films. 

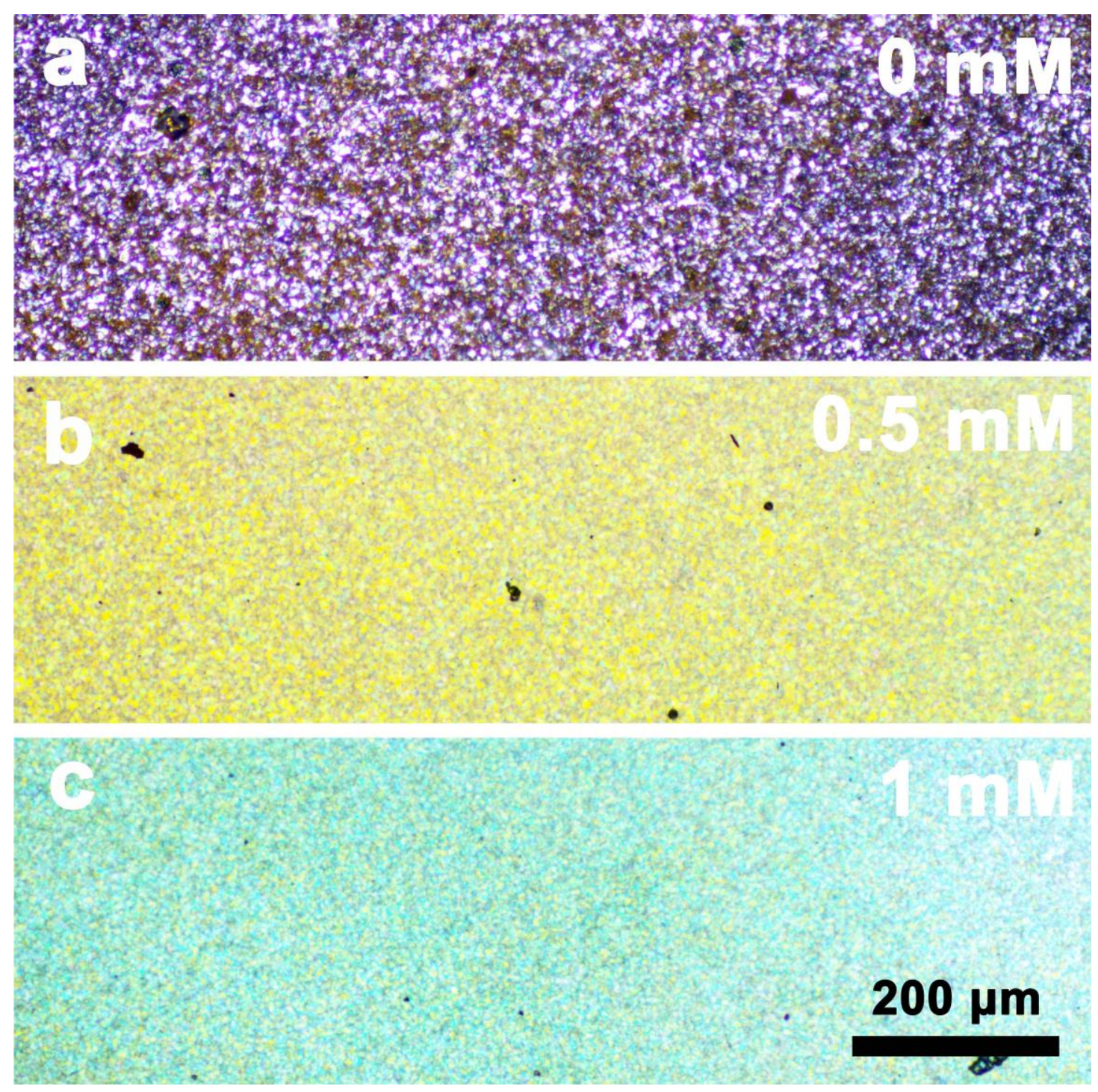

Figure S10. POM images of CNC/PVA-GA films showing clear birefringence and brilliant color, from red (a), yellow (b), and blue (c), respectively, corresponding to containing three different concentrations $(0 \mathrm{mM}, 0.5 \mathrm{mM}$, and $1 \mathrm{mM})$ of $\mathrm{NaCl}(\mathrm{aq})$. 


\section{0 month}

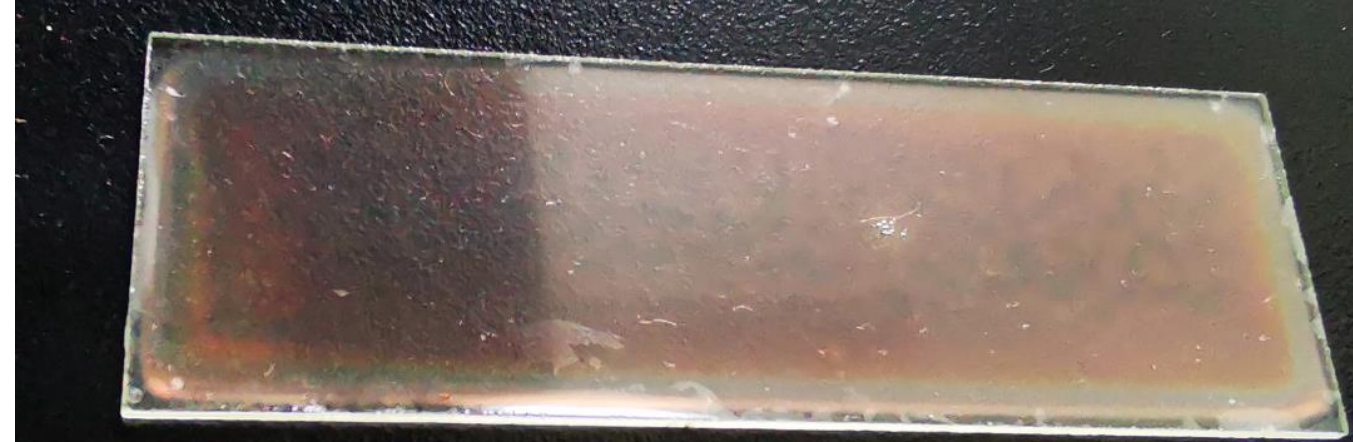

\section{2 months}

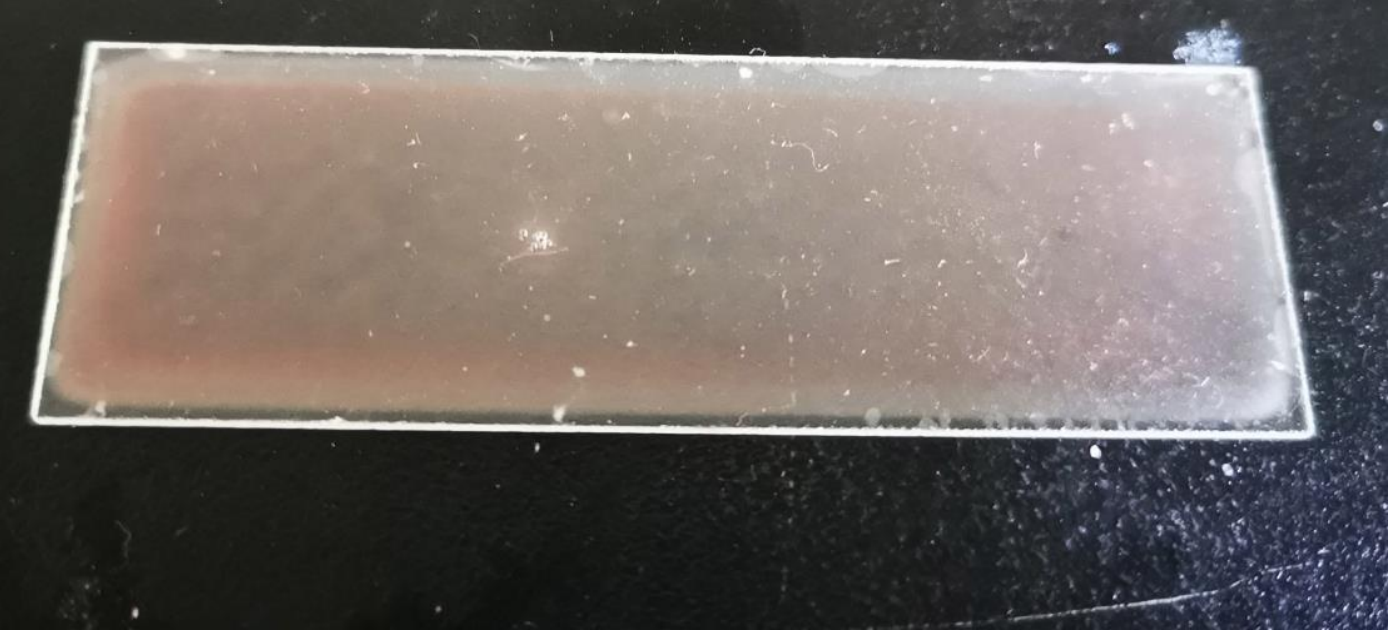

Figure S11. Photographs of CNC/PVA-GA coating on the glass after exposure to water for two months. 

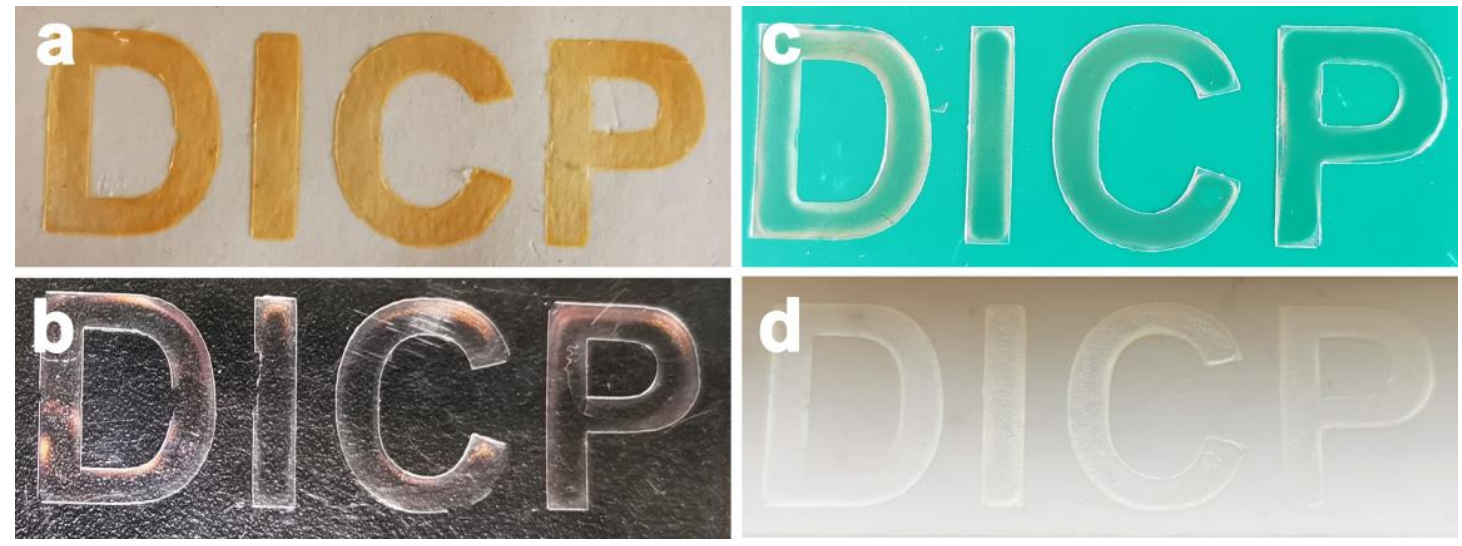

Figure S12. Photographs of CNC/PVA-GA coating on the paperboard (a), polystyrene plastic (b), rubber (c), and ceramic (d) with the "DICP" pattern. 


\section{Supporting tables}

Table S1. Mechanical properties of the different mass ratios of CNC/PVA composites as a function of PVA content.

\begin{tabular}{|c|c|}
\hline CNC/PVA (w/w) & Tensile strength (MPa) \\
\hline $100: 0$ & $49 \pm 6$ \\
\hline $90: 10$ & $65 \pm 6$ \\
\hline $80: 20$ & $75 \pm 6$ \\
\hline $70: 30$ & $104 \pm 4$ \\
\hline $60: 40$ & $89 \pm 2$ \\
\hline $50: 50$ & $72 \pm 7$ \\
\hline $40: 60$ & $75 \pm 3$ \\
\hline $30: 70$ & $60 \pm 6$ \\
\hline $0: 100$ & $41 \pm 7$ \\
\hline
\end{tabular}


Table S2. Mechanical properties of CNC film, CNC/PVA-70:30, and CNC/PVA-GA composites.

\begin{tabular}{|c|c|c|c|}
\hline Sample & $\begin{array}{c}\text { Young's modulus } \\
(\mathbf{G P a})\end{array}$ & $\begin{array}{c}\text { Tensile strength } \\
\mathbf{( M P a )}\end{array}$ & $\begin{array}{c}\text { Strain-at-break } \\
\mathbf{( \% )}\end{array}$ \\
\hline CNC & $7.1 \pm 0.9$ & $49 \pm 6$ & $0.7 \pm 0.1$ \\
\hline CNC/PVA-70:30 & $5.8 \pm 1.8$ & $104 \pm 4$ & $1.9 \pm 0.8$ \\
\hline CNC/PVA-GA & $4.9 \pm 0.5$ & $113 \pm 6$ & $2.3 \pm 0.2$ \\
\hline
\end{tabular}


Table S3. The detailed addition amount for the photonic CNC/PVA composite films.

\begin{tabular}{|c|c|c|}
\hline Sample & $\begin{array}{r}\mathbf{2} \text { wt \% CNC } \\
(\mathbf{m L})\end{array}$ & $\begin{array}{c}\mathbf{2} \text { wt \% PVA } \\
(\mathbf{m L})\end{array}$ \\
\hline CNC/PVA-90:10 & 9.0 & 1.0 \\
\hline CNC/PVA-80:20 & 8.0 & 2.0 \\
\hline CNC/PVA-70:30 & 7.0 & 3.0 \\
\hline CNC/PVA-60:40 & 6.0 & 4.0 \\
\hline CNC/PVA-50:50 & 5.0 & 5.0 \\
\hline CNC/PVA-40:60 & 4.0 & 6.0 \\
\hline CNC/PVA-30:70 & 3.0 & 7.0 \\
\hline
\end{tabular}

